\title{
Initial assessment of air pollution from electricity generation using renewable energy and management in Thailand
}

\author{
W. Phoochinda \\ School of Social and Environmental Management, \\ National Institute of Development Administration, Thailand
}

\begin{abstract}
The objectives of this study are 1) to investigate air pollution produced from electricity generation using renewable energies of a VSPP (very small power producer) and to assess the air pollution incurred in each process 2) to investigate the air pollution management of the renewable energy power plants studied; and 3 ) to suggest appropriate air pollution management for the power plants in each process of their electricity generation. Data are collected using in-depth interviews with the environmental management personnel of the 13 renewable energy power plants studied.

The results show that in the scope of this study, wind and solar energies do not produce air pollution problems compared to other renewable energies. Biomass and refuse derived energies produce more air pollution in each process of the electricity generation especially the combustion process.

Measures in the air pollution management are suggested as follows: 1) Regarding transportation, there should be a system in following up and supervising the transportation of the raw materials to the plant and measures in preventing particulate emissions and the spillage of the raw materials along the way. 2) Regarding storage, the raw materials should be stored in a proper condition and the storehouse should be located far away from a residential community; and 3) Regarding electricity generation, the technology employed should be efficient resulting in complete combustion and there should be an appropriate system in treating the pollutants resulting from the combustion.

Keywords: renewable energy, air pollution, management, solar, wind, hydro, biomass, biogas, wastewater, geothermal.
\end{abstract}




\section{Introduction}

Nowadays the rate of energy consumption keeps increasing due to the rapid and constant growth in the economic, transportation and industrial sectors. As a result, it is vital that energy should be sufficiently supplied in response to the need to develop the country as well as to facilitate the citizens' lives. In addition, increasing the public awareness in saving energy is of no less importance. New power plants have been constructed in order to satisfy the increasing demand for electricity, which approximately rises by 1,400 megawatts per year, or equivalent to the production capacity of two new electricity power plants each year for Thailand. Moreover, the private sector is involved as Independent Power Producer, Small Power Producer and, Very Small Power Producer. Most of the energy sources in electricity generation at present are non renewable energies natural gas about $70 \%$, lignite and coal $20 \%$, crude oil $1 \%$, water energy $5 \%$, other renewable energies $2 \%$ and imported electricity $2 \%$ [1].

Renewable energies such as small water sources and biomass are gaining interest in electricity generation for their practicality - as they are widely available and environmentally friendly, make the effective use of the natural resources, help reduce dependence on imported energy and fortify the country's energy supply. As a result, the government has various policies in support of electricity production from renewable energy such as adder cost and tax incentive. Though environmental impacts caused by electricity generation from renewable energy are relatively smaller when compared to the electricity currently produced from non renewable energy, the impacts are still considerable, especially those resulting from the combustion resulting in air pollution.

According to the data from the US (EPA [2]), in the US, electricity generation causes more air pollution problems than other activities do. The percentage of sulfur dioxide, nitrogen oxide, and carbon dioxide emission is $67 \%, 23 \%$, and $40 \%$ of all the emission of these gases from all other activities. With respect to the amounts of air pollution caused by different types of energy used in one megawatt of electricity generation, carbon dioxide is emitted most in solid waste-fired electricity generation and coal fired electricity generation. Sulfur dioxide is emitted considerably more in the electricity generation from coal and oil compared to the generation of the same amount of electricity when other sources of energy are used. And nitrogen oxide is emitted more in the electricity generation from coal, oil, and solid waste combustion than from other types of energy.

\section{Research methodology}

In order to collect the data in this study, the electricity generation and air pollution management of a very small power producer using renewable energy are observed, their officers in charge thereof are interviewed, and the literature concerning the existing standards and measures in the environmental 
management, especially air pollution of the power plants imposed by the relevant organizations is reviewed.

The target subjects are very small power producer using renewable energy with the production capacity of less than ten megawatts, including two biomass power plants, three refuse-derived power plants, one biogas power plant, two wind energy power plants, two hydro power plants, one geothermal power plant and two solar power plants.

Data-collection Tools used included 1) in-depth interview of the electricity generation of very small power producers and 2) observation forms related to each step of electricity generation

\section{Results and discussion}

In this study, the findings are reported in two related parts. The first part reports on the analysis of the air pollution impacts resulting from electricity generation by very small power producers. And the second part discusses the measures in air pollution management and solution of the existing air pollution impacts.

\subsection{Analysis of the air pollution resulting from electricity generation by very small power producer}

As shown in Figure 1, the scope employed in assessing the air pollution incurred in electricity generation is based on the impacts resulting from raw material acquisition transportation and storage, electricity generation, and waste management; the input and output in all of which are as follows.

In assessing the air pollution incurred in electricity generation by very small power producers using renewable energy, the findings can be concluded as follows:

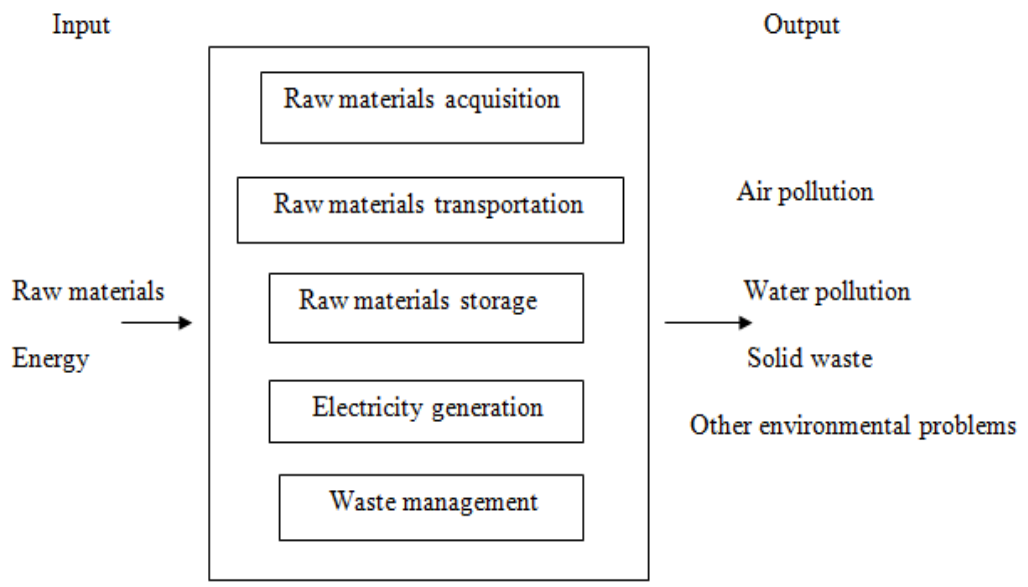

Figure 1: The scope employed in assessing the air pollution incurred in electricity generation by very small power producer. 


\subsubsection{Biomass}

Biomass is used the most as renewable energy as compared to other renewable energy in Thailand as we are an agricultural country. Biomass is cleaner than fossil fuel as it contains virtually no sulfur and the fuel-bound nitrogen in biomass is also significantly lower than in coal, which may help reduce emissions of NOx [3]. However, biomass still incurs some air pollution like green house gases of $46 \mathrm{~g} / \mathrm{kWh}$, oxides of nitrogen of $2.5 \mathrm{~g} / \mathrm{kWh}$, sulfur dioxide of $0.302 \mathrm{~g} / \mathrm{kWh}$ and total suspended particles of $0.2 \mathrm{~g} / \mathrm{kWh}$ [4].

In agricultural processes like rice harvesting and milling, biomass is acquired as a byproduct, though, together with some dust particles; depending on the type, transportation, and transference of the biomass. For biomass transportation, certain fuel like oil or natural gas is used and subsequently causes some air pollution. Biomass also requires space for fuel storage as well as systems for moving it from storage areas to boilers. In the storage of the biomass, there are some dust particles left behind. To deal with this problem, the power plants under observation have the roof and wall of the storehouse covered all around with shading net. Besides, water is sprayed to prevent the spread of dust particles. In the transference process, the fork lift truck is used, and fuel is needed to power the truck as well as for the conveyor belts, of which there are two types - the closed and open ones, in feeding the raw material into the electricity generation system. The use of the fork lift truck as well as the opentype conveyor belt pose problems from fugitive dust particles.

In generating electricity from biomass, the biomass prepared is then used as fuel in the combustion in order to produce steam. Certain air pollutants are emitted during the combustion. The most common ones which need to be monitored with reference to the standard allowed are sulfur dioxide $\left(\mathrm{SO}_{2}\right)$ nitrogen oxide (NOx) and particulate matters. Sometimes there is also some tar left behind in the combustion chamber. The steam from the boiling water is used to turn the turbines and run the generators, during which; however, there is some noise problem from the engines used. For the waste management, the ash from the combustion must be disposed of properly or can be recycled.

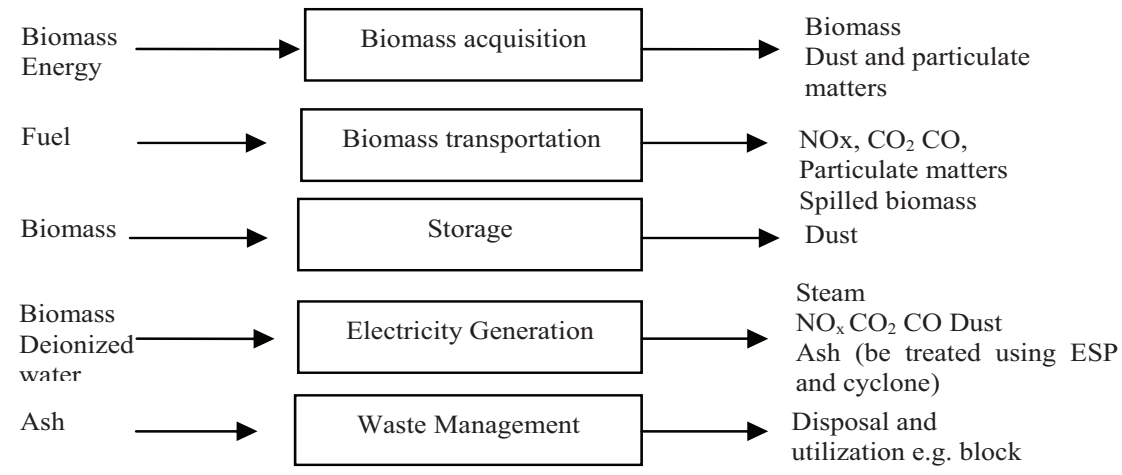

Figure 2: $\quad$ Pollution from electricity generation using biomass. 


\subsubsection{Refuse derived fuel}

The use of refuse as the raw material in electricity generation discussed in this study concerns two methods: the use of refuse as a fuel in the combustion or in the form of heat energy and the use of landfilled solid waste which will lead to decomposition and subsequent methane fuel.

As for the use of refuse to produce heat, in the combustion the materials mostly used in the plants observed are food and organic wastes, with plastic, paper, glass and metal wastes coming behind. Combustible waste with not too high moisture content is hand-sorted through the conveyor belt, which is powered by electricity. In the observation, though the waste sorting personnel use individually protective equipment, they are not fully protected. There are also problems of the odour and hazardous wastes. For the transportation and transference of the refuse, the power plant with the refuse sorted in the premises only needs to have it transferred through the conveyor belt or by a fork lift truck, both of which involve some spillage. But for the refuse sorted outside the plant, fuel is required in its transportation, which leads to air emissions. Spillage is also possible if the refuse is not properly wrapped or covered with shading net. The burning of solid waste to produce the heat used in the boilers, in addition to the hot steam used to drive the turbine and generator, leads to certain air pollutants including dust particles, nitrogen oxide (NOx), carbon dioxide, carbon monoxide, as well as some possible noise pollution from the electricity generators. The ash left behind from the combustion can be utilized and if it is toxic, need to be properly treated.

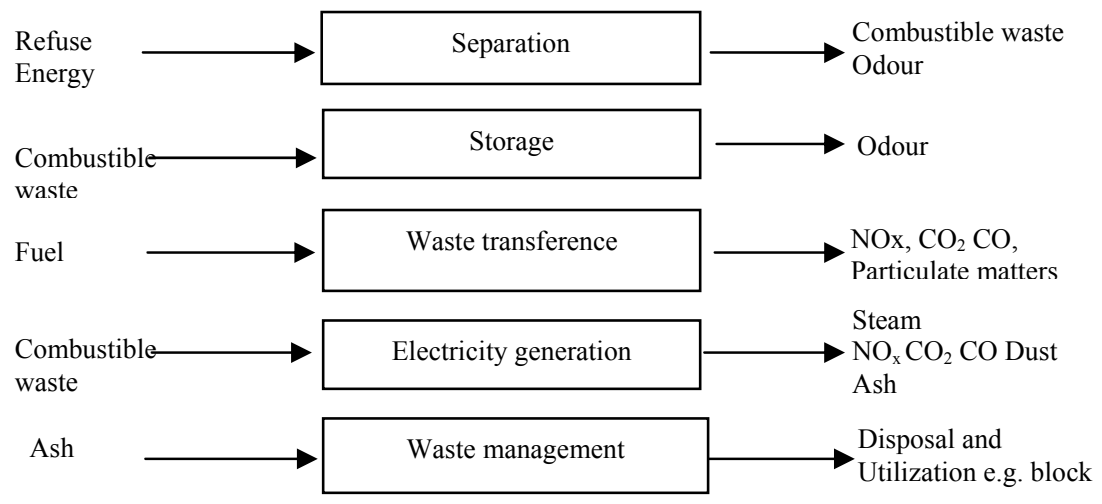

Figure 3: Pollution from electricity generation using refuse.

For landfill energy, solid waste used as the raw material is hand-sorted by people using some personnel protective equipment through the conveyor belt, which is powered by electricity. Only biodegradable and non-hazardous refuse is used in the secured landfill. The subsequent environmental impacts include bad odour and spillage during transportation and separation. In transporting the solid waste, which must be wrapped in proper plastic to the landfill site, there is some air pollution, depending on the energy used. The landfill must be properly 
conditioned to prevent undesirable environmental impacts for example by lining it with High Density Polyethylene, and installing gas collection pipes and leachate collection pipes. The end product from the landfill is methane gas, which is used in electricity generation. In addition, there are carbon dioxide and a little amount of other gases, as well as leachate, which must be treated. In the electricity generation from the methane acquired, there is some noise pollution from the engines such as the electricity generators. In terms of the management of the waste from the process, like leachate and non-biodegradable waste left behind, appropriate disposal and treatment are applied.



Figure 4: Pollution from electricity generation by secured landfill.

\subsubsection{Wastewater}

In the process of raw material preparation, wastewater is collected in the wastewater collection ponds through electric pumps. Before being conveyed to the fermentation ponds, such wastewater must be conditioned in order to adjust its acidity. Usually the power plant producing electricity from biogas created by wastewater treatment is located within the premises where the wastewater collection ponds are thus only pipe is needed in the transportation. When the wastewater has been adjusted to the right condition, it is pumped to the fermentation ponds, where certain microorganisms and chemical substances are added to make the fermentation condition appropriate. The final product is methane gas. There are also carbon dioxide, hydrogen sulfide, residues, the treated water and odour. The biogas to be used in electricity generation must be conditioned, for example having its moisture content reduced and particulates removed. In such processes, certain chemical substances and energy are used, leaving some residue and odour behind. In the process of electricity generation using the biogas acquired, there is some noise pollution from the machines involved. In the waste management, the wastewater from the fermentation process is treated in the stabilization ponds or with other methods and can be used for watering plants. The residues left behind, if toxic, need to be properly treated. 

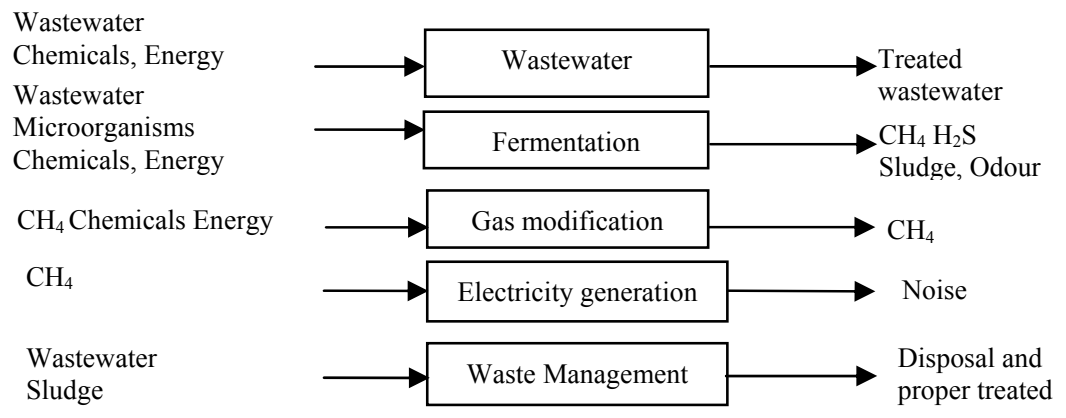

Figure 5: $\quad$ Pollution from electricity generation using wastewater.

\subsubsection{Geothermal energy}

In the raw material acquisition process, getting the geothermal energy in the form of hot water and hot steam to generate electricity involves drilling, which requires some energy and water. The water mineral content depends on the source and water temperature. From the observation of the plants studied, the temperature of the hot water and steam acquired is not high enough to generate electricity, thus working fluid is added to raise the temperature and it is reused. In the drilling, there is some air pollution caused by the fuel used and some noise pollution from the machines used. In the electricity generation process, the hot steam is used to drive the turbines and electricity generators. In accordance with Kagel et al. [5] pollution caused by electricity generation using geothermal energy is negligible as there is no combustion of any fuel.

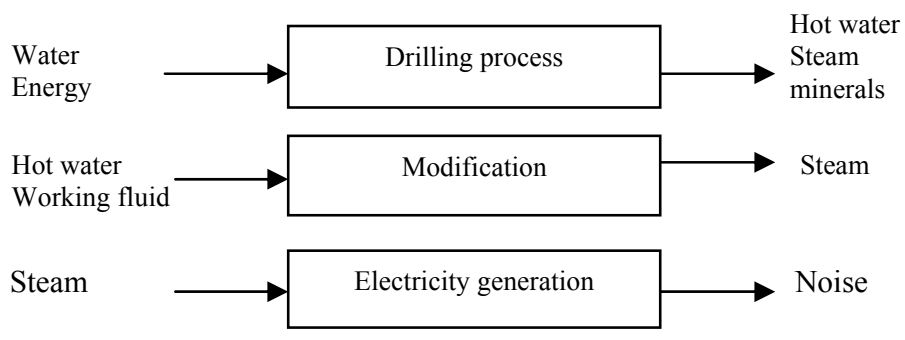

Figure 6: Pollution from electricity generation using geothermal energy.

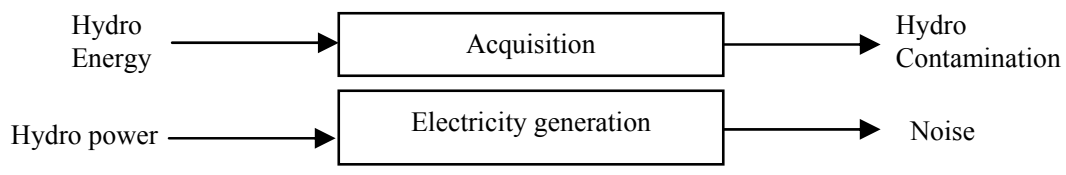

Figure 7: $\quad$ Pollution from electricity generation using hydro power. 


\subsubsection{Hydro power}

In the raw material acquisition, water is pumped or collected using certain energy. Filters are used to prevent dirt particles from damaging the machines involved. In using hydro power to produce electricity, water pressure is used to drive the generators as a potential energy, causing some noise impacts from the machines involved.

\subsubsection{Wind energy}

Electricity can be produced directly from the wind energy used to drive the generator. In addition to some noise caused by the turbines and generators, electricity generation using wind energy results in negligible air pollution.



Figure 8: $\quad$ Pollution from electricity generation using wind energy.

\subsubsection{Solar energy}

Solar energy can be directly used to produce electricity through solar cells. The electricity acquired must be appropriately converted using the inverter. In the scope of the air pollution referred to in this study, electricity generation using solar energy does not cause any air pollution.

\subsection{Measures in air pollution management of very small power producer}

Electricity generation using water, wind and solar energy incur negligible air pollution. For electricity generation using biomass and refuse derived energy, in which combustion is involved, there are pollution problems in every step analyzed. Besides, there are wastewater and residues left behind in the process of water preparation to produce hot steam. This study suggests the measures in air pollution management in every step of electricity generation of very small power producer ranging from the raw material acquisition to the disposal of waste from electricity production.

\subsubsection{Biomass and combustible refuse}

The raw material source should be in the vicinity to the power plant for the convenience in transportation and storage. Apart from the problem of the moisture content, biomass particulates can diffuse and refuse can stink. Another point of concern is that the supply must be sufficient to satisfy the required production capacity. It is thus advisable to make a contract with reliable suppliers and stock the raw materials in case of the lack thereof. The raw materials should have an appropriate level of moisture content, for example less than $30 \%$ for wood waste. Those with high level of moisture content must be left in the sun to dry or left for some time in the storehouse for their moisture content to decrease. Besides, they should be broken down to very small or suitable sizes 
for their complete combustion. There should not be a lot of particulates mixing with the biomass.

During the transportation, the trucks used should be covered with cloth to prevent spillage and particulate emissions. The trucks used in transporting the raw materials must be regularly checked with their transportation details recorded and followed up (GSP). In the storage, the raw materials should be kept in a storehouse with a translucent roof in order that the sunlight can help reduce the moisture content of the raw materials, and with a secure wall to prevent the moisture from outside and the particulate emissions. If the storehouse is in a residential community, it should be covered with shading net for better prevention of particulate emissions. Besides, water should be sprayed around the heap of the raw materials and no smoking signs should be placed in the area. In conveying the raw materials to the burning oven, proper measures should be applied in preventing spillage and fugitive particulate emissions. Operational personnel and those who are in the vicinity must use personal protective equipment (PPE).

In the combustion, the combustion chamber should be of high efficiency, for example that in the fluidized bed incinerators [6], which give complete combustion and leave no tar residue behind. In electricity generation, the heat from the combustion is used to change the water in the boiler into steam in order to drive the turbines and generators. However, the water must be appropriately conditioned before. With respect to the treatment of the pollutants from the combustion, mainly the air pollution from the particulates, sulfur dioxide, nitrogen oxide; apparatus for air pollution treatment like Cyclone, Electrostatic Precipitation (ESP), and Wet Scrubber are used. The pollutants treated must pass the standards set by the Department of Industrial Works and the Pollution Control Department, which must regularly check whether the quality of the air emitted from the exhaust pipes meets the standards required or used (Continuous Emission Monitoring System: CEMS.) For water pollution, wastewater must be further treated, for example in the stabilization pond and oxidation pond and then can be recycled if there is no contamination left behind. The residues, if found toxic, must be properly treated before being recycled. For the wastes or byproducts, like ash from the combustion, if considered hazardous, there must be notification on their disposal according to the processes required by the Department of Industrial Works. If not considered hazardous, there must be identification of their recycling, for example in production of bricks. Such wastes or byproducts must be properly kept in order to prevent particulate emissions. Growing perennial plants like tall trees and medium sized bushes around the power plants can help prevent particulate emissions, noise impact and odour to the residential community in the vicinity.

\subsubsection{Landfill refuse}

The amount appropriate for the electricity generation using landfill refuse is over one million tons [7]. Sorting refuse is of importance, in order to separate biodegradable or organic waste from non-organic waste and separate refuse that can cause explosion on landfill property. Sorting refuse is carried out through the 
conveyor belts by personnel who must use personal protective equipment like gloves, boots, and mouth covering cloth. The refuse must be wrapped with specially thick plastic according to the standard set in its transportation to prevent water from dampening it and prevent spillage on the way. The deck of the truck used should be covered with cloth.

For the preparation of the landfill, the size must be appropriate to the amount of the refuse, with the depth of at least 12 meters, and working capacity of no less than 20 years, and with anti-seepage system covering all over the bottom and side surfaces before the refuse is filled in. After the landfill is filled up, or there is no more use of the property, the landfill is to be closed with anti-seepage lining. Clay or synthetic lining sheets with low seepage rate can be used. According to the standard set, a layer of sheets made of compressed clay of $60 \mathrm{~cm}$. in thickness with the seepage rate of less than $1 \times-10^{7} \mathrm{~cm}$ per second, or sheets made of High Density Polyethylene: HDPE with the thickness of at least $1.5 \mathrm{~mm}$ can be used to line all the interior [8]. A pipe system must be installed in order to collect and dispose of the leachate. There must be a rain water drainage system separated for the rainwater falling onto the landfill. Above the antiseepage layer, the pipe system collecting the leachate is installed consisting of PVC or HPDE pipes of at least 4 inches in diameter, with holes and covered with synthetic fiber filter sheets and placed within a layer of pebble or round sand, with the seepage rate of less than $1 \times-10^{7} \mathrm{~cm}$ per second and of not less than $30 \mathrm{~cm}$. in thickness. The quality of the wastewater discharged outside the landfill property must be within the criteria standard of disposed wastewater quality according to the Industrial Works Act [8]. Bio-extract should be sprayed in order to reduce the odour from the landfill and the refuse.

In extracting the biogas, there must be a system to ventilate and control the gas resulting from the decomposition of the refuse in the landfill, which is mainly methane, to prevent the explosion, fire and disturbing odour. The system controlling the gas in the landfill must be designed to prevent the concentration of the methane gas. In order to control the ventilation of the methane gas from the landfill, a pipe must be placed vertically and the equipment to extract the gas from the landfill which is called Active Control must be installed in order to exploit the gas as fuel. In the case that there is a large amount of landfill gas, the gas must be burned with flares. The resulting gas must be disposed of in compliance with the air quality standard. For the gas relay pipe and gas measuring equipment, there must be regular examination to prevent leakage, and the concentration of the gas must be regularly measured. There must be quality improvement and cleansing of the gas, for example to remove water, carbon dioxide, corrosive substances, alkaline metal and particulates.

In electricity generation, the biogas from a general landfill, which consists of $50 \%$ methane gas, $40-50 \%$ carbon dioxide, $0.5-1 \%$ of hydrogen, oxygen, nitrogen, and other gases; is used to drive the turbines and generators.

\subsection{3 wastewater}

Wastewater with considerably high dirt content of COD:N: P 100:2.2:0.4 is suitable for fermentation to produce methane gas which can be used in energy 
production as biogas. The raw material (wastewater) should be in the same area for the convenience of conveying it to the wastewater treatment system. The wastewater must be of adequate amount and with the COD content at the appropriate and stable level. In treating wastewater through fermentation, the treatment condition and treatment technology employed must be appropriate, for example the Anaerobic Fixed Film system. The biogas acquired from the fermentation, which may be contaminated, must be treated before being used for electricity generation, for example by using the Wet Scrubber and gas moisture reduction equipment.

\subsubsection{Other renewable energy}

For geothermal energy, wind, hydro and solar energy, there is negligible air pollution as there is no combustion process and so the measure for air pollution are not addressed.

\section{Conclusion and suggestion}

Though renewable energy are considered quite clean, using them in electricity generation results in some air pollution in various steps. According to the analysis of the air pollution with reference to the scope of raw material acquisition, raw material transportation, raw material storage, electricity generation, waste management; it is found that the biomass and refuse derived energy bring about air pollution problem in their every step of electricity generation. The biogas energy produced from wastewater incurs less air pollution problems than the biomass energy as there is no combustion, the step which can most negatively affect the environment when compared to other steps. Whereas electricity generation using wind and that using solar energy cause least environmental impact.

This study suggests the measures in the environmental management in electricity generation using renewable energies as follows;

Measures concerning raw material acquisition - The raw materials should be in the vicinity to the power plant, and are in sufficient amount and of appropriate quality. It is advisable to have viable backup raw material sources and make a purchase contract for the materials which must be purchased.

Measures concerning transportation - There should be a system in supervising the transportation of the raw materials to the plant and in preventing the spillage of the raw materials along the way, for example by using shading net to cover them.

Measures concerning storage - the raw materials should be properly stored for the convenience of use. The raw materials in the categories of biomass and refuse should have low moisture content and of the amount sufficient for the production and should be stored in a closed area in order to prevent particulate emissions.

Measures concerning electricity generation - the technology employed should be appropriate and efficient. 
Measures concerning waste management - the waste incurred should be appropriately recycled. In case of hazardous wastes, relevant offices must be notified.

\section{Suggestion on/concerning policies}

1. The government should provide appropriate support on the electricity generation using renewable energy based on the real circumstances, such as the amount of the raw materials and available resources. And there should be restriction on the concession granted for electricity generation using renewable energy that causes air pollution.

2. The measures and standards used at present are not inclusive of all the pollutions incurring, but only cover those which are evident such as air pollution and water pollution. Moreover, at present there is yet no environmental measure nor standard clearly applicable to very small size power plants. Thus, analysis of every step of electricity generation using renewable energy is essential in order to find out/come up with suggestions on comprehensive environmental management measures.

3. A power plant with production capacity of less than 1 megawatt, which does not need to obtain concession in order to generate electricity, should be under the supervision of a local office, as its electricity generation may cause some environmental impacts

\section{References}

[1] Energy Policy and Planning Department, 2008. Annual Report 2008. Bangkok Energy Policy and Planning Department, Ministry of Energy.

[2] US. EPA. n.d. a Clean Energy: Air Emission. Online. http:www.epa.gov /rdee/energy-and-you/affect/air-emissions.html

[3] Easterly J. L. and Burnham M. 1996. Overview of Biomass and Waste Fuel Resources for Power Production. Biomass and Bioenergy. 10(2-3), pp. 79-92.

[4] Sukkumnoed D. 2006. Better Power for Health: Healthy Public Policy and the future of sustainable energy in Thailand.

[5] Kagel. A., Bates D. and Gawell K. 2007. a Guide to Geothermal Energy and the Environment. United States of America: Geothermal Energy Association.

[6] Buranasak Madmai. 2009. Biomass to Energy. Technology Promotion Association. 36. (April-May): 63-65.

[7] US. EPA. n.d. b. Landfill Methane Outreach Program. Online. http: //www.epa.gov/imop/index.html

[8] Department of Pollution Control. Ministry of Science Technology and Science. 2001. Standard Measures and Guidelines for Community Garbage Management. $5^{\text {th }}$ Edn .Bangkok: Kurusapha the Teachers Council of Thailand. 